This is an electronic reprint of the original article. This reprint may differ from the original in pagination and typographic detail.

Author(s): Siitonen, Marko

Title: Identity and Online Groups

Year: $\quad 2018$

Version:

Please cite the original version:

Siitonen, M. (2018). Identity and Online Groups. In H. Giles, \& J. Harwood (Eds.), Oxford Encyclopedia of Intergroup Communication. Oxford University Press. https://doi.org/10.1093/acrefore/9780190228613.013.449

All material supplied via JYX is protected by copyright and other intellectual property rights, and duplication or sale of all or part of any of the repository collections is not permitted, except that material may be duplicated by you for your research use or educational purposes in electronic or print form. You must obtain permission for any other use. Electronic or print copies may not be offered, whether for sale or otherwise to anyone who is not an authorised user. 
Siitonen, M. (forth.). Identity in online groups. In H. Giles \& J. Harwood (Eds.) Oxford Encyclopedia of Intergroup Communication. New York: Oxford University Press. DOI: 10.1093/acrefore/9780190228613.013.449

\title{
IDENTITY AND ONLINE GROUPS
}

\author{
Summary \\ Questions related to identity have been central to discussions on online communication since \\ the dawn of the Internet. One of the positions advocated by early Internet pioneers and \\ scholars on computer-mediated communication was that online communication would differ \\ from face-to-face communication in the way traditional markers of identity (such as gender, \\ age, etc.) would be visible for interlocutors. It was theorized that these differences would \\ manifest both as reduced social cues as well as greater control in the way we present \\ ourselves to others. This position was linked to ideas about fluid identities and identity play \\ inherent to post-modern thinking. Lately, the technological and societal developments related \\ to online communication have promoted questions related to, for example, authenticity and \\ traceability of identity. \\ In addition to the individual level, scholars have been interested in issues of social identity \\ formation and identification in the context of online groups and communities. It has been \\ shown, for example, how the apparent anonymity in initial interactions can lead to heightened \\ identification/de-individuation on the group level. Another key question related to this one is \\ the way group identity and identification with the group relates to intergroup contact in online \\ settings. How do people perceive others' identity, as well as their own, in such contact \\ situations? To what extent is intergroup contact still intergroup contact, if the parties involved \\ do not perceive it as such? As online communication continues to offer a key platform for \\ contact between various types of social groups, questions of identity and identification remain
}


at the forefront of scholarship into human communication behavior in technology-mediated settings.

\section{Keywords}

computer-mediated communication, intergroup communication, intergroup contact, online communities, social identity, technology-mediated communication

\section{Introduction}

A look back at the origins of contemporary online communication reveals that one of the central ideas behind the creation of computer networks was to enable the functioning of interactive groups and communities (Licklider \& Taylor, 1968). Issues related to identity and online groups are explored, beginning with the early years of hope and hype and extending all the way to recent examples where the Internet has already been established as an integral part of the global social reality.

Volumes have been written on questions of identity in online settings, and it is not possible to cover every viewpoint on the matter. The concentration here is on matters that bear relevance to intergroup communication online, such as the process of building social identity, identification, and de-individuation, and the questions online settings may pose to understanding and facilitating intergroup communication.

\section{Early Internet and the Question of Identity Online}

As the term new media suggests, an important part of the discourse surrounding advancements in technologically mediated communication is the thought that advances in communication technology might offer something different and new compared to earlier modes of communication. In the case of online networks, one of these apparently new 
elements has been related to the question of identity. For example, one of the positions advocated by early Internet pioneers and scholars on computer-mediated communication was that online communication would differ from face-to-face communication in the way traditional markers of identity (such as gender, age, etc.) would be visible for interlocutors. This position was in line with the way computer-mediated communication was theorized in the 1980s and early 1990s, where it was often pointed out how social cues were being filtered out in online communication (Culnan \& Markus, 1987), how online communication was not as rich as other forms of communication (Daft \& Lengel, 1984), or how the new affordances might be utilized in deception (e.g., Rheingold, 1993).

While some of the early approaches emphasized the way computer-mediated communication might be lacking the affordances of face-to-face communication, or be inferior to it, there were scholars who approached the topic from an opposite angle. They posited that the apparent anonymity of the online world would present a positive force, allowing for people to transcend the limitations of the face-to-face reality. An illustrative example of the discourse from this particular time, and a more hopeful approach to identity in online groups comes from Bromberg (1996), who argued that "For many, MUDs and chat networks are 'just a game' or 'just another form of communication'; for others, they offer an antidote to loneliness and malaise, allow the exploration of alternate identities and personae, offer the promise of connectivity and community and allow users to experience the feeling of mastery over their environments" (p. 146).

The idea of exploring alternate identities was a powerful one. It was fairly typical of early scholarship into online groups and communities to predict that the emerging network society would soften existing social boundaries, allowing for individuals a higher level of mobility regarding status, class, social roles, and character (e.g., Jones, 1999). This freedom has been characterized in many ways, for example as a capacity "to manipulate our 'selves' and to 
multiply them indefinitely" (Filiciak, 2006, p. 88) or to "rewrite one's own identity outside of traditional constraints" (Hand \& Moore, 2006, p. 177). It bears similarities to the idea that our contemporary global and technology-mediated reality may lead to a wider range of source materials to "imagine with" when it comes to constructing subjectivities (Appadurai, 1996, p. $53)$.

While there is an element of truth to emphasizing the new and the different, experience has shown us that people can be both surprisingly quick in incorporating technological advancements into their everyday lives, and surprisingly conservative in the way they utilize the new affordances presented to them (e.g., Kendall, 1998). For example, regarding identity play, even in online game spaces where role-playing - the very act of playing as somebody else - could be expected to be common, the vast majority of people have been shown not to be overly interested in activities such as "gender-bending" (Kolo \& Baur, 2004), while actually playing regularly with acquaintances they know in so-called real life (Yee, 2005). Indeed, despite the fluid affordances presented to them in online context, people have been shown to engage in impression management in a similar fashion known from face-to-face encounters: emphasizing an ideal of authenticity while choosing to utilize at least some impression management techniques (such as concealing information) that help them present themselves in a socially desirable way (Chester, 2004).

With an ever-increasing number of global Internet users, it has become clear that the online world most certainly does not exist in a vacuum, but that it has become entwined within the larger communication infrastructure of our societies (Jones, 1997). Indeed, by the early 2000 s the Internet already had become a tool used routinely by ordinary people in their everyday lives (Haythornthwaite \& Wellman, 2002). While the affordances of computermediated communication can definitely be seen as differing from face-to-face communication when it comes to performing certain aspects of identity, some things have become apparent. 
Firstly, people have learned to adapt to the new communication landscape presented to them, making dichotomies such as online/offline or real/virtual lose a lot of their relevance.

Secondly, while it may be tempting to see the online world as separate from the physical one, this is largely an illusion. Facets of our offline personae, such as socioeconomic status, cultural background, gender identification, and the like, often do end up making a difference in online social interaction as well—whether we acknowledge it or not (e.g., O’Brien, 1999). In short, many of the early approaches to computer-mediated communication were too quick to see- or hope for-fundamental changes in people's behavior, and to attribute these changes to characteristics of technology.

\section{Building Social Identity Online}

Jenkins (2008) sees identity as a complex, ongoing mapping of our social reality and our place in it. What this view entails is the idea that identity, or rather, identification, is always a process with multiple stakeholders - never fixed, and never in the hands of one actor alone. Furthermore, adopting a process-view brings with it a temporal element. Building and maintaining identity takes time. As Jenkins notes, identity should be seen as a practical accomplishment, coming about through a constant negotiation of similarities and differences within and between individuals and social groups. These starting points naturally also apply to group identification and categorization, and bring us to the concept of social identity, a process of collective identification that becomes especially salient in intergroup settings.

What is it that we base our understanding of ourselves and of others on in online settings? There is no simple answer to this question, as one can say that the emergence of social identity in online groups occurs through multiple pathways, including self-disclosure and participation in the group's activities, as well as all other forms of communication and social 
interaction within the broad network of the online (and offline) environment where the group operates.

Regarding the question of intentionality, there are at least two lines of thinking one can follow. The first one highlights that the building of social identity can be seen as an intentional activity, related to impression management. For example, emphasizing intentionality is in line with one aspect of the idea of so-called hyperpersonal relationship development (Walther, 1996), which posits that online communication often affords better control over what kind of an image is being conveyed, or performed, to one's communication partners. The second line of thinking reminds us that since people are typically aware of the possibility of tactical impression management in online settings, they may value knowing the other parties outside the online realm as well, or tend to trust identity-related information that is based more on concrete and long-term activity, not on expression. For example, it is fairly usual that long-term collaboration between online group members also takes on some form of offline contact (e.g., Kendall, 1998).

Regarding physical reality as a source of authenticity when speaking about identity, while many people continue to put emphasis on it, and even though we have already seen that the online environment is not as free of offline influences as some early scholars suggested, one should not put too much stress on the question of whether an online identity, such as a pseudonym, can be fully traced back to a physical person or not. Rather, concepts such as reputation and trust can be approached from a very pragmatic point of view where everyday activities and social interaction are emphasized. Just like in offline contexts, knowing someone (our relationship with them, their reputation) is connected to issues such as our willingness to help them out or trust their word. For example, without relevant contextual information a pseudonym of an online group member may look totally anonymous to an outsider. However, members of the same in-group will be able to appreciate the history and 
reputation behind the pseudonym, making it fully recognizable in its own right (Donath, 1999).

A similar process of slow and incremental building of identity occurs not only on an individual level, but rather on the level of groups as well. Through continuous social interaction and joint endeavors, groups define themselves as well as others. For example, group-specific rituals or ceremonies have the power to strengthen people's sense of social identity and location. In other words, they help people experience community (Cohen, 1989). Similarly, reciprocal interaction, such as giving and receiving social support, is connected with group identity — even more so than, for example, sheer time spent online (e.g., Howard \& Magee, 2013).

As always, the processes of identification through which we build a sense of self, and our membership in in-groups, necessarily also include recognizing out-groups. We sort people not only into "us" but also into "them," and this kind of practically automatic social categorization has a strong influence on both individual and group levels (see, e.g., social identity theory by Tajfel \& Turner, 1979). It comes as no surprise, then, that group membership and social identity have been shown to be salient in online contexts as well as offline. Furthermore, what this implies is that also in online contexts we can expect to see that group members' perceptions toward other groups might be biased (Howard \& Magee, 2013).

The question of identification becomes even more interesting when contrasted against the affordances (or limitations, if one chooses to approach them that way) of online communication. Previous research has explored the social identity model of deindividuation effects (SIDE), which posits that apparent anonymity (like not seeing one's interlocutor) actually enhances group-level social identity, that is, leads to heightened identification with and conforming to the in-group (Reicher, Spears, \& Postmes, 1995). The type of selfcategorization that the SIDE model talks of with an emphasis on, for example, lack of 
personalizing cues, and lack of identifiability to out-group, can often be seen taking place in the context of online groups.

The SIDE model helps explain how and why anonymity or pseudonymity in those online settings where group identity is salient may enhance social influence processes and lead to outcomes where conforming to group norms is exaggerated. For example, members of an online group with a political agenda that is societally non-normative may perceive they are among like-minded others, even if the group itself is public, open, and contains multiple voices. This perception then leads to social identity, rather than individual identity, being activated, and to a situation where group norms guide individuals' actions (Carr, Varney, \& Blesse, 2016). An important point to note here is that the SIDE model does not prescribe that any one technology in itself leads to certain outcomes, but rather reminds us that as always, we need to be aware of the context in which interaction occurs. It is a combination of social and technological factors that are at play here.

Research utilizing the SIDE model has not only looked at the cognitive dimension, but also the strategic use of expressing group identities in computer-mediated (CMC) contexts. For example, if an individual evaluates that revealing their gender identity may be unbeneficial to them, or lead to unwanted consequences, they may want to utilize the affordances of CMC to hide or obscure their gender (Spears, Lea, Postmes, \& Wolbert, 2011). While acknowledging the possibilities for strategic performance of group identity, recent scholarship also points out how the rise of social media and social networking sites in the 2000s has come to mean that individuals' participation in various groups has become much more visible than was the case with older Internet channels, such as discussion boards (Carr et al., 2016). Interestingly enough, our contemporary online environment often features a high amount of both deindividuating and personalizing cues. This reality presents an interesting challenge, as well as possibilities, for developing scholarship in intergroup communication. 
What the online communication context has allowed for is the creation of new types of social groups in addition to the ones that exist in the offline world. These range from globespanning anonymous peer support forums to online multiplayer communities to networks engaged in crowdsourcing, and may present salient social categories like those found outside of the online contexts.

\section{Facilitating Intergroup Communication in Online Settings}

The question of how to improve intergroup contact and reduce intergroup bias has interested scholars for decades (for a history of the Contact Hypothesis, see, e.g., Dovidio, Gaertner, \& Kawakami, 2003). There has been a considerable body of research into this area, much of which has been drawing on or extending Allport's (1954) Intergroup Contact Theory. Put simply, intergroup contact theory suggests that (1) equal status between the groups in the contact situation, (2) cooperation, (3) common goals, and (4) support of the surrounding infrastructure (e.g., authorities, law, or custom) all factor in reducing intergroup conflict and promoting positive outcomes and attitudes. As a meta-analysis of more than 500 studies demonstrated, there are indeed considerable positive effects to intergroup contact to be gained (Pettigrew \& Tropp, 2006). These were especially prevalent if the four prerequisites of Allport's theory were satisfied, but it must be noted that the four conditions were by no means essential for positive effects to emerge. It is particularly relevant to notice that most of the studies in the field have looked at face-to-face settings, or simply been conducted in a time before the Internet and other information and communication technologies expanded into mainstream social consciousness. Therefore, we will now turn our gaze to a number of questions related to the nature of intergroup contact in contemporary online settings, and studies that have put the topic of intergroup contact online into play. 
The very first question we must answer is simply what do we mean by intergroup contact online? The intergroup contact theory (Allport, 1954), as well as the work that preceded it, was originally interested in racial and ethnic encounters. As Dovidio et al. (2003) note in their overview of the history of contact theory, early studies looked at, for example, contact between 'black' and 'white' soldiers or race relations in public institutions such as schools. In other instances, the grouping has been deliberately made evident by the researchers, such as is often the case in experimental research design. What this means is that for the most part, the tradition of studies into intergroup contact has not had to problematize the question of group membership. It is important to recognize this starting point, because for intergroup communication to occur in the first place, social, rather than personal, identity has to be salient. Clear group membership is also seen as a necessary element from the viewpoint of reducing intergroup bias. Studies have shown that in order for intergroup bias to be reduced as a result of successful interaction, out-group members must be perceived as typical members of their group. This so-called typicality is important because otherwise we easily attribute possible positive outcomes and characteristics to the individual, who is seen as atypical, instead of changing our attitudes toward the social group the person represents (Hewstone \& Brown, 1986). However, as we have seen, the questions of identity and identification gain a new twist when entering the realm of online communication. Quite simply, traditional category-identifying information might not be readily available, or even strategically concealed, which in turn might force us to critically examine our initial assumptions concerning intergroup communication and its possible manifestations online.

When thinking about possibilities for facilitating intergroup communication online it is important to remember that social categorization is not set in stone. Rather, it is a dynamic process capable of change. Over time, scholars looking into intergroup contact have provided several avenues into positive change in people's perceptions and attitudes. 
The first step one could take is quite simply "learning about others" (Pettigrew, 1998). The idea behind this approach is that acquiring new, non-stereotypical information of others may increase the likelihood of people seeing each other as individuals instead of just representatives of social groups. Given that an increase in information concerning one's interlocutors is linked to reducing uncertainty, this approach can be very effective in improving intergroup relations. For example, a study looking at language-specific group lessons and activities in a virtual environment (Second Life) illustrated how virtual meetings may foster cross-cultural encounters and friendships, greater awareness of insider cultural perspectives, and openness toward new viewpoints (Diehl \& Prins, 2008). Learning about others can be linked to personalization, a type of decategorization. This approach encourages more personalized (intimate) interactions (Miller, 2002). A complex collection of processes such as self-disclosure, increasing an interpersonal focus in intergroup interaction, may lead to breaking the perception of an out-group as a homogenous unit, emphasizing individuating features of out-group members, and ultimately promoting empathy and familiarity (Miller, 2002). On the other hand it must be noted that while positive examples exist, communication in online groups may also emphasize differentiation between "us" and "them," as well as distribution of one-sided information and stereotypical views of "the other."

Yet another possible route is to, for example, seek to alter group members' perception of their in-group boundaries to include others who were previously not included in it. This type of restructuring or redefining existing group categorizations is called recategorization. The idea behind recategorization is that if group members change their perceptions, for example to include earlier out-group members as part of a larger, joint group, this may help to reduce outgroup bias (e.g., Gaertner \& Dovidio, 2000). A practical example of this approach can be found in a study looking at Canadian and Iranian students participating in a joint online experiment with positive outcomes. The seven-week-long study demonstrated how this type 
of intervention has the potential of contributing to a positive change in attitudes, as well as the development of more complex and realistic image of the other (Tavakoli, Hatami, \& Thorngate, 2010). The outcome of the study highlights how positive changes in attitudes can happen even if the perception of cultural dissimilarities persists, which is in line with earlier research on intergroup communication.

While it may seem counter-intuitive at first, it has been proposed that the very characteristics of computer-mediated communication that may make group categorization more difficult have the potential to make it easier to facilitate improved intergroup contact (Walther, 2009). These include factors such as inability to see the physical features of interlocutors (visual anonymity), the practicality of organizing contact via computer-mediated means as opposed to the physical reality, and being freed of the anxiety-inducing reality of face-to-face encounters with members of the out-group, among others (Amichai-Hamburger \& McKenna, 2006).

\section{Questions for the Future}

Looking at issues of identity and online groups continues to offer interesting avenues for future research - especially so when combined with an intergroup perspective. For example, the context of online communication offers multiple ways to enable and study intergroup relations - that is, actual intergroup interaction — something that has been lacking attention in past decades (Pettigrew \& Tropp, 2006). Questions such as how people construct group membership and group categories through communication may benefit from being able to look at social interaction in its naturalistic settings and over longer periods of time than it is viable to do in controlled experiments.

Online contexts may also provide settings that almost naturally highlight or challenge concepts related to research into intergroup contact. For example, much of the so-called 
sharing economy, as well as social media developed in the 2010s, relies on or expects for people to trust relative strangers. As noted, trust is one of the key components required in improving intergroup relations, which in turn means that social media studies could benefit from an intergroup perspective, and vice versa.

Another set of interesting questions for future research deals with interventions and their possible effects. One of the long-standing questions of research into improving intergroup contact is the concept of transfer or generalization of effects - that is, whether changes in attitudes resulting in one social context may generalize to new situations, even to whole outgroups not involved in the original contact (see, e.g., Miller, 2002). At least on the level of attitudes it seems that the answer is yes, as intergroup contact effects have been shown to systematically extend beyond the initial situation (Pettigrew \& Tropp, 2006). On the other hand, as Dovidio, Gaertner, Saguy, and Halabi (2006) note in their review, intergroup attitudes do not necessarily lead into changed actions or orientations. Intergroup contact in online settings represents yet another, often very specific, context that highlights the importance of inquiring further into the question of generalization. For example, because the whole notion of what is intergroup contact is not always that clear in online settings, or whether the groups one deals with are at all similar to those existing outside the technologymediated contexts, we cannot take for granted that the effects would be exactly the same as have been verified before. It is also interesting to note how many of the studies looking for intergroup contact online approach their topic from the point-of-view of existing face-to-face social groups, such as national, religious, or ethnic groupings, instead of choosing an approach where groups and communities native to online contexts would be used as a starting point. Clearly, more research into the question of facilitating intergroup contact with the help of online interventions is needed (cf., Walther, 2009). 
Talking of the generalization of positive effects of intergroup contact, we must also come back to the question of representation and perceived group membership. Miller (2002) notes that, "In sum, then, generalization of positive intergroup contact occurs when contact occurs with outgroup members who are perceived as representative of that particular outgroup" (p. 392). From the viewpoint of improving intergroup attitudes, could it be that indicators of group membership should at times be consciously emphasized in online settings, depending of course on the goals set for the intervention, and whether the contact is or was positive in the first place? Or is emphasizing group membership rather a liability, leading to increased polarization and a reality where using social media actually reduces opportunities for positive intergroup communication (see, e.g., Hayes, Smock, \& Carr, 2015)?

Finally, there are several questions related to control and power, regardless of whether its source can be traced to human or nonhuman actors. For example, questions of authenticity and traceability of identities that were first sparked at the dawn of the Internet are still of relevance today. The increase of so-called walled gardens by various commercial and statelevel actors wishing to control who people are when they are online can be seen as narrowing the opportunities to engage in identity play. Another form of control can be seen in the proliferation of algorithms used to filter our communication landscape, whether social networking sites or news, including what groups we may belong to, or be associated with. The impact of such external, and often unseen, forces on the formation and stability of social groups as well as on potential intergroup communication asks for a critical review.

\section{Discussion of the Literature}

There are several threads of scholarship that have been touched upon. Each thread continues to attract new research, and may offer interesting questions for upcoming researchers. 
The first thread is the body of research looking into the development, affordances, and uses of computer-mediated communication. This line of research began in earnest in the 1980s, with scholars being interested in how certain characteristics of computer-mediated communication might affect communication. Over the next decades, new viewpoints were introduced, many of which highlighted the importance of human agency and capability for adaptation. As our technology-rich communication landscape keeps on developing into new directions, it is likely that there will continue to be open questions for researchers to tackle here.

The second thread of research explores questions of identity and identification in online contexts. Here, scholars have been and continue to be interested in the positive and negative effects of anonymity, concepts of playful identities and identity theft, and the many ways in which social identities are built in action. Again, technological development as well as people's capability to adapt their behavior to changing situations helps surface new angles from which to approach these questions.

The third thread revolves around the question of facilitating intergroup contact, especially with the help of affordances provided by new media. The ease and reach of online communication allows for interesting experiments to be conducted, some of which are directly relevant or related to face-to-face contexts as well. It is this line of research that holds great potential for positive change but has to also tackle the negative and detrimental sides of communication within and between online groups.

\section{Further Reading}

Chester, A., \& Bretherton, D. (2007). Impression management and identity online. In A.

Joinson, K. McKenna, T. Postmes, \& U. D. Reips (Eds.), The Oxford handbook of Internet psychology (pp. 223-236). Oxford: Oxford University Press. 
Hewstone, M., \& Brown, R. (Eds.). (1986). Contact and conflict in intergroup encounters. Cambridge, MA: Basil Blackwell.

Postmes, T., \& Baym, N. (2005). Intergroup dimensions of Internet. In J. Harwood \& H. Giles (Eds.), Intergroup communication: Multiple perspectives (pp. 213-238). New York: Peter Lang.

Postmes, T., Spears, R., \& Lea, M. (2002). Inter-group differentiation in computer mediated communication: Effects of depersonalization. Group Dynamics, 6, 3-16.

Spears, R., \& Postmes, T. (2015). Group identity, social influence, and collective action online: Extensions and applications of the SIDE model. In S. S. Sundar (Ed.), The handbook of the psychology of communication technology (pp. 23-46). West Sussex, U.K.: Wiley-Blackwell.

Suler, J. R. (2002). Identity management in cyberspace. Journal of Applied Psychoanalytic Studies, 4, 455-460.

Turkle, S. (1995). Life on the Screen: Identity in the Age of the Internet. New York: Simon and Schuster.

Wagner, U., Tropp, L. R., Finchilescu, G., \& Tredoux, C. (Eds.). (2008). Improving intergroup relations: Building on the legacy of Thomas F. Pettigrew. Malden, MA: Blackwell.

Walther, J. (2006). Nonverbal dynamics in computer-mediated communication, or :( and the net :('s with you, :) and you :) alone. In V. Manusov \& M. Patterson (Eds.) The SAGE handbook of nonverbal communication (pp. 461-480). Thousand Oaks, CA: SAGE.

Walther, J., \& Parks, M. (2002). Cues filtered out, cues filtered in. Computer mediated communication and relationships. In M. Knapp \& J. Daly (Eds.), Handbook of interpersonal communication (3d ed., pp. 529-563). Thousand Oaks, CA: SAGE.

\section{References}


Allport, G. W. (1954). The nature of prejudice. Cambridge, MA: Addison-Wesley.

Amichai-Hamburger, Y., \& McKenna, K. Y. A. (2006). The contact hypothesis reconsidered: Interacting via the Internet. Journal of Computer-Mediated Communication, 11(3), 825-843.

Appadurai, A. (1996). Modernity at large: Cultural dimensions of globalization. Minneapolis: University of Minnesota Press.

Bromberg, H. (1996). Are MUDs communities? Identity, belonging, and consciousness in virtual worlds. In R. Shields (Ed.), Cultures of Internet: Virtual spaces, real histories, living bodies (pp.143-152). London: SAGE.

Carr, C. T., Varney, E. J., \& Blesse, J. R. (2016). Social media and intergroup communication: Expanding identification and collapsing contexts. In H. Giles, \& A. Maass (Eds.), Advances in intergroup communication (pp. 155-173). New York: Peter Lang.

Chester, A. (2004). *Presenting the self in cyberspace: Identity play in MOOs[https://minerva-access.unimelb.edu.au/handle/11343/38846]* (Doctoral dissertation). University of Melbourne. Retrieved 1.9.2016 from

Cohen, A. (1989). The symbolic construction of community. Chichester, U.K.: Ellis Horwood.

Culnan, M., \& Markus, M. (1987). Information technologies. In F. Jablin, L. Putnam, K. Roberts, \& L. Porter (Eds.). Handbook of organizational communication: An interdisciplinary perspective (pp. 420-443). Newbury Park, CA: SAGE.

Daft, R., \& Lengel, R. (1984). Information richness: A new approach to managerial behavior and organizational design. In L. Cummings \& B. Staw (Eds.), Research in organizational behavior 6 (pp. 191-233). Greenwich, CT: JAI Press. 
Diehl, W. C., \& Prins, E. (2008). Unintended outcomes in Second Life: Intercultural literacy and cultural identity in a virtual world. Language \& Intercultural Communication, 8(2), $101-118$.

Donath, J. (1999). Identity and deception in the virtual community. In M. Smith \& P. Kollock (Eds.), Communities in cyberspace (pp. 29-59). London: Routledge.

Dovidio, J. F, Gaertner, S. L., \& Kawakami, K. (2003). *Intergroup contact: The past, present, and the future[http://dx.doi.org/10.1177/1368430203006001009]*. Group Processes \& Intergroup Relations, 6(1), 5-21.

Dovidio, J. F., Gaertner, S. L., Saguy, T., \& Halabi, S. (2006). From when to why: Understanding how contact reduces bias. In U. Wagner, L. R. Tropp, G. Finchilescu, \& C. Tredoux (Eds.), Improving intergroup relations: Building on the legacy of Thomas F. Pettigrew (pp. 75-90). Malden, MA: Blackwell.

Filiciak, M. (2006). Hyperidentities: Postmodern identity patterns in massively multiplayer online role-playing games. In M. Wolf \& B. Perron (Eds.), The video game theory reader (pp. 85-102). New York: Routledge.

Gaertner, S. L., \& Dovidio, J. F. (2000). Reducing intergroup bias: The common intergroup identity model. Philadelphia: Psychology Press.

Hand, M., \& Moore, K. (2006). Community, identity and digital games. In J. Rutter \& J. Bryce (Eds.), Understanding digital games (pp. 166-182). London: SAGE.

Hayes, R. A., Smock, A., \& Carr, C. T. (2015). Face [book] management: Self-presentation or political views on social media. Communication Studies, 66, 549-568.

Haythornthwaite, C., \& Wellman, B. (2002). The Internet in everyday life: An introduction. In B. Wellman, \& C. Haythornthwaite (Eds.), The Internet in everyday life (pp. 3-44). Oxford: Blackwell. 
Hewstone, M., \& Brown, R. (1986). Contact is not enough: An intergroup perspective on the “contact hypothesis.” In M. Hewstone \& R. Brown (Eds.), Contact and conflict in intergroup encounters (pp. 1-44). Cambridge, MA: Basil Blackwell.

Howard, M. C., \& Magee, S. M. (2013). To boldly go where no group has gone before: An analysis of online group identity and validation of a measure. Computers in Human Behavior, 29(5), 2058-2071.

Jenkins, R. (2008). Social identity (3d ed.). London: Routledge.

Jones, S. (1997). The Internet and its social landscape. In S. Jones (Ed.), Virtual culture: Identity and communication in cybersociety (pp. 7-35). London: SAGE.

Jones, S. (1999). Understanding community in the information age. In P. Mayer (Ed.), Computer media and communication: A reader (pp. 219-240). Oxford: Oxford University Press.

Kendall, L. (1998). Meaning and identity in "cyberspace": The performance of gender, class, and race online. Symbolic Interaction, 21(2), 129-153.

Kolo, C., \& Baur, T. (2004). Living a virtual life: Social dynamics of online gaming. Game Studies, 4(1).

Licklider, J., \& Taylor, R. (1968, April). The computer as a communication device. Science and Technology, 76, 21-41.

Miller, N. (2002). Personalization and the promise of contact theory. Journal of Social Issues, 58(2), 387-410.

O’Brien, J. (1999). Writing in the body: Gender (re)production in online interaction. In M. Smith \& P. Kollock (Eds.), Communities in Cyberspace (pp. 76-104). London: Routledge.

Pettigrew, T. F. (1998). Intergroup contact theory. Annual Review of Psychology, 49, 65-85. 
Pettigrew, T. F., \& Tropp, L. (2006). A meta-analytic test of intergroup contact theory. Journal of Personality and Social Psychology, 90, 751-783.

Reicher, S., Spears, R., \& Postmes, T. (1995). A social identity model of deindividuation phenomena. European Review of Social Psychology, 6, 161-198.

Rheingold, H. (1993). The virtual community: Homesteading on the electronic frontier. Reading, MA: Addison-Wesley.

Schlenker, B. (2003). Self-presentation. In M. Leary \& J. Tangney (Eds.), Handbook of self and identity (pp. 492-518). New York: Guilford.

Spears, R., Lea, M., Postmes, T., \& Wolbert, A. (2011). A SIDE look at computer-mediated interaction. In Z. Birchmeier, B. Dietz-Uhler, \& G. Stasser (Eds.), Strategic uses of social technology: An interactive perspective of social psychology (pp. 16-39). Cambridge, U.K.: Cambridge University Press.

Tajfel, H., \& Turner, J. C. (1979). An integrative theory of intergroup conflict. In W. G. Austin \& S. Worchel (Eds.), The social psychology of intergroup relations (pp. 33-48). Monterey, CA: Brooks Cole.

Tavakoli, M, Hatami, J., \& Thorngate, W. (2010). Changing stereotypes in Iran and Canada using computer mediated communication. Journal of Intercultural Communication, 23.

Walther, J. (1996). Computer-mediated communication: Impersonal, interpersonal and hyperpersonal interaction. Communication Research, 23(1), 3-43.

Walther, J. B. (2009). Computer-mediated communication and virtual groups: Applications to interethnic conflict. Journal of Applied Communication Research, 37(3), 225-238.

Yee, N. (2005, October 15). *Playing with someone [http://www.nickyee.com/daedalus/archives/001468.php]*. Daedalus Project. 